\title{
O percurso da decisão para estabelecimento de um curso bacharelado com dupla titulação
}

O presente artigo tem como objetivo identificar elementos presentes no processo decisório para estabelecimento de um curso bacharelado com dupla titulação envolvendo duas instituições de ensino, sendo uma brasileira e outra portuguesa. Para alcançar esse intento, realizou-se um estudo de caso acerca do processo decisório não estruturado, considerando os doze elementos básicos propostos por Mintzberg et al. (1976). Com relação aos fins, a pesquisa é descritiva, de natureza qualitativa, utilizando como meios para obtenção de dados diferentes fontes. Pode-se identificar que o processo decisório possui um alto nível de complexidade, principalmente ao considerar os fatores dinâmicos que o influenciam. Constata-se que o processo decisório pesquisado apresenta diversos atores, diferentes estratégias e interesses, fazendo com que grande parte do tempo seja dedicado ao desenvolvimento do projeto e ainda, valer-se de habilidade política em busca de consenso para aprovação da proposta.

Palavras-chave: Processo decisório; Organização; Estratégia; Internacionalização.

\section{The decision route for the establishment of a bilateral course with a double diploma}

\begin{abstract}
The present article aims to identify elements present in the decision - making process for the establishment of a bachelor 's degree with a double degree involvin two teaching institutions, one Brazilian and the other Portuguese. In order to achieve this, a case study of the unstructured decision-making process was carried out, considering the twelve basic elements proposed by Mintzberg et al. (1976). Regarding the ends, the research is descriptive, of qualitative nature, using as means to obtain data from different sources. One can identify that the decision process has a high level of complexity, especially when considering the dynamic factors that influence it. It is observed that the decision-making process researched presents several actors, different strategies and interests, causing much of the time to be dedicated to the development of the project and also, to use political skill in search of consensus to approve the proposal.
\end{abstract}

Keywords: Decision-making process; Organization; Strategy; Internationalization.

Topic: Ensino Superior, Pesquisa e Extensão

Reviewed anonymously in the process of blind peer.
Received: 22/03/2019

Approved: $27 / 08 / 2019$
Sheldon William Silva (iD)

Instituto Federal do Norte de Minas Gerais, Brasil

http://lattes.cnpq.br/5691436224279198

http://orcid.org/0000-0002-2473-5728

sheldonwilliamsilva@gmail.com

Tuane Ferreira Melo

Universidade Federal de Lavras, Brasil

http://lattes.cnpq.br/7003071033672294

tuaneferreiramelo@gmail.com
Referencing this:

SILVA, S. W.; MELO, T. F.. O percurso da decisão para estabelecimento de um curso bacharelado com dupla titulação. Educationis, v.7 , n.2, p.1-13, 2019. DOI: http://doi.org/10.6008/CBPC23183047.2019.002.0001 


\section{INTRODUÇÃO}

Tomar uma decisão é inevitável. Cotidianamente, variadas situações apelam por um sim ou por um não e requerem análise diante dessa escolha. No estudo das organizações, os gestores assumem um papel central no processo de tomada de decisão, que envolve um conjunto de ações e fatores dinâmicos em um ambiente de novidades, complexo e ambíguo (MINTZBERG et al., 1976).

O processo decisório no ambiente organizacional não se restringe apenas à escolha de uma alternativa e sim, a todo o processo que inicia com as várias possibilidades de ação perante uma decisão e finaliza com a escolha de um compromisso para implementação. Hatch (1997) apresenta alguns modelos de tomada de decisão, sendo eles: o modelo racional, o modelo de coalisão, o modelo tentativas e erros e o modelo garbage can. Para a autora, o nível de concordância ou entendimento entre os atores envolvidos sobre o método e objetivos a serem alcançados, irá influenciar ou determinar o modelo de tomada de decisão.

Eisenhardt et al. (1992) trazem outros elementos como a tecnologia utilizada, a ambiguidade nos objetivos, o conjunto de informações e a influência do poder como fatores significativos em um processo decisório. Nesse contexto, o presente artigo tem como objetivo identificar elementos presentes no processo decisório para estabelecimento de um curso bacharelado com dupla titulação envolvendo duas instituições de ensino, sendo uma brasileira e outra portuguesa.

$\mathrm{Na}$ segunda seção dessa pesquisa serão apresentadas quatro dimensões acerca do processo decisório: a dimensão racional; a dimensão normativa; a dimensão política, de poder e de recursos; a dimensão da 'anarquia organizada' e dos sistemas frouxamente articulados. Essa seção se dedica ainda a referenciar a pesquisa de Mintzberg et al. (1976) com relação ao processo decisório não estruturado, considerando os doze elementos básicos identificados por esses autores para posterior análise do caso pesquisado.

A terceira seção cuidará dos aspectos metodológicos do trabalho, características, objetivos, meios e finalidade da pesquisa. Adiante, na seção quatro serão apresentados os resultados oriundos da investigação. $\mathrm{Na}$ quinta seção serão apresentadas as considerações finais, bem como as limitações e sugestões de novas pesquisas, encerrando com as referências utilizadas nesse artigo.

\section{REVISÃO TEÓRICA}

\section{O processo decisório e suas dimensões}

Essa seção tem como objetivo apresentar o referencial teórico que sustenta o estudo proposto. Diante dessa proposição, realiza-se um percurso pela literatura referente ao processo decisório apresentando quatro dimensões de análise: a dimensão racional; a dimensão normativa; a dimensão política e de poder; a dimensão da 'anarquia organizada' e dos sistemas frouxamente articulados. 


\section{Dimensão racional}

A concepção mecanicista racional presente nos estudos de Taylor e Fayol ganharam um enfoque processual com a burocracia weberiana. Essas características permitem identificar a dimensão racional presente no processo decisório a partir da lógica tecnocrata, aliada a instrumentos precisos e planejados para garantir uma boa administração (MORGAN, 1996).

Segundo Simon (1965), por uma boa administração se entende o comportamento objetivamente adequado ao seu fim. Por isso, desenvolveu o processo decisório que consiste em escolhas de alternativas e meios adequados para se atingir um determinado fim. $\mathrm{O}$ autor ainda adverte que há uma limitação cognitiva do (s) indivíduo (s) envolvidos no processo decisório, influenciada por elementos como: a) o comportamento do indivíduo, b) a influência do fator temporal, c) a capacidade cognitiva e o conhecimento do indivíduo ou do grupo, d) a complexidade do ambiente, e) os conflitos entre os atores, f) as informações disponíveis e g) os sistemas de valores validados por cada indivíduo ou organização.

De acordo com Simon (1965), o processo decisório na concepção de racionalidade limitada consiste em: a) prospecção, análise do problema ou situação, b) concepção, criação de alternativas para a resolução do problema e c) decisão, julgamento e escolha das alternativas. Enfim, uma decisão será considerada racional quando for considerada ótima por todos os membros da organização.

Devido à complexidade do processo decisório, Simon (1965), Eisenhardt et al. (1992) e Hatch (1997) entendem que não há possibilidade de haver um processo absolutamente racional uma vez que falta conhecimento sobre as consequências de todas as alternativas. Considerando que essas consequências são futuras, seria impossível determinar se os resultados alcançados pela escolha de uma alternativa são sempre melhores que os resultados que seriam alcançados se a escolha fosse outra.

\section{Dimensão normativa}

Após analisar o processo decisório de um grande número de organizações, Mintzberg et al. (1976) apresentam um modelo que busca sintetizar, de forma não linear e racional, um processo decisório não estruturado. São identificados doze elementos: três fases, três rotinas de suporte e seis fatores dinâmicos. Essas categorias serão utilizadas como modelo de análise para o estudo de caso dessa pesquisa. Sendo assim, dar-se-á maior destaque nesses elementos na seção quatro. O conceito 'não estruturado' se refere a um processo decisório que ocorre de forma não totalmente estruturada, não determinada, ou que vai se conformando ao longo do processo.

Mintzberg et al. (1990), discutem as dificuldades que a temática 'processo decisório' apresenta pois, quando não se trabalha com modelos, a pesquisa tende a apresentar de forma apenas descritiva o processo e quando desenvolve modelos, pode-se incorrer no problema apenas prescritivo do processo. Nesse sentido, Butler enfatiza a importância e o papel que os modelos mecanicistas-burocráticos apresentam, uma vez que possibilitam identificar padrões recorrentes ao processo decisório, embora diversos processos possam apresentar interrupções ou maior complexidade. 
De acordo com Pettigrew (1977), a tomada de decisão deve ser analisada teoricamente e empiricamente e que há, de fato, grandes desafios nos estudos sobre processo decisório. O autor enfatiza a importância de se compreender a inter-relação entre os níveis de análise, a interconectividade entre passado, presente e futuro, os antecedentes históricos, as condições e as trajetórias de cada organização.

\section{Dimensão política, de poder e de recursos}

De acordo com March (1962), as organizações empresariais devem ser percebidas como um sistema político, na qual existem unidades básicas consistentes, que possuem sua própria preferência e poder decisório. Diante dessa relação, a escolha das alternativas apresentadas pelo sistema gera conflitos, pois as unidades não conseguem ao mesmo tempo maximizar sua escolha diante dos recursos do sistema. Corroborando, Pettigrew (1977) o comportamento político é definido como um comportamento de indivíduos ou, em termos coletivos, subgrupos dentro de uma organização que reivindicam a distribuição de recursos organizacionais.

Segundo Eisenhardt et al. (1992), o modelo político é uma reação às premissas sociais sobre grupos, uma vez que as pessoas são racionais individualmente, mas não coletivamente. A premissa chave é a de que as organizações são coalizões de pessoas com interesses competitivos e/ou concorrentes. Assim, as características do modelo político são: (a) a organização é vista como um sistema político de preferências parcialmente conflitantes; (b) a tomada de decisões estratégicas reflete as preferências das pessoas poderosas; (c) as pessoas se envolvem em política.

Pfeffer et al. (2003) partem da visão de que as organizações são fortemente controladas por fatores externos. Elas são interdependentes: transacionam entre si para obter recursos (não controlados por ela) e para fornecer recursos (que estão sob seu controle). No contexto social ou ambiente social, os participantes (organizações, grupos, indivíduos) que controlam/detêm recursos mais críticos e escassos apresentam maior poder de influência sobre o ambiente e, consequentemente, sobre outras organizações.

\section{Dimensão da 'anarquia organizada' e dos sistemas frouxamente articulados}

Sobre a Teoria Organizacional e as perspectivas moderna, simbólica e pós-moderna, trata-se de um modelo apresentado por Hatch (1997) que contrasta fortemente com o modelo racional de tomada de decisão. De acordo com a autora, o processo decisório é um conjunto não racional de eventos em que os objetivos não podem ser claramente definidos, bem como não se pode conhecer antecipadamente todas as alternativas circunscritas à resolução dos problemas.

Corroborando, Cohen et al. (1972), propuseram o modelo 'garbage Can', no qual as organizações são vistas como 'anarquias organizadas' pôr as considerarem como ambientes altamente ambíguos, complexos e instáveis, dificultando um processo decisório bem estruturado. O garbage can é também descrito como uma confluência aleatória de quatro fatores: a) as oportunidades de escolha, b) soluções, c) participantes e d) preocupações das pessoas dentro e fora da organização. Outra observação importante é que, aparentemente, à medida que tempo progride o âmbito das decisões aumenta, os participantes se tornam 
mais variados e o número de soluções se torna maior.

Weick (1976) ao investigar o processo decisório em Universidades explora a dificuldade de se estabelecer mecanismos eficientes de coordenação e controle nas devido à sua característica de ambientes complexos e ambíguos. O conceito de 'Loosely Coupled System' sugere que as articulações em um sistema não seriam tão sólidas como se pregava, sendo na maioria das vezes infrequentes, fracas e de pouca importância, devendo ser compreendidas como sistemas semiautônomos de decisões.

Mais tarde, Orton et al. (1990) revisitam o conceito de 'Loosely Coupled Systems' devido as distorções verificadas na sua aplicação, causados por fatores como o modo de difusão da linguagem organizacional, foco em apenas uma dimensão de análise e a dificuldade em capturar elementos indeterminados, incertos e ambíguos. Sendo assim, os autores consideram que um sistema loosely coupling, deverá apresentar simultaneamente, dois elementos: responsiveness (capacidade de responder às demandas em um dado período de tempo) e distinctiveness (capacidade de responder de forma diferenciada a demandas de diversas naturezas).

\section{METODOLOGIA}

O objetivo principal desta pesquisa é identificar elementos presentes no processo decisório para estabelecimento de um curso bacharelado com dupla titulação envolvendo duas instituições de ensino. De acordo com Speller et al. (2011), entende-se por dupla titulação o reconhecimento de um título de graduação ou pós-graduação em dois países automaticamente, mediante um acordo entre duas universidades, no caso, uma brasileira e outra estrangeira, regulamentando o processo.

A pesquisa adota um caráter descritivo, levando-se em consideração o fato de que a mesma pretende identificar os elementos presentes no processo decisório acerca de um projeto de dupla titulação para um curso de bacharelado em Administração, envolvendo duas instituições de ensino, uma brasileira e outra portuguesa, as quais serão nominadas de IESB e IESP respectivamente, por questões de sigilo (GIL, 2002; RAUPP et al., 2003).

Quanto à abordagem, a pesquisa é qualitativa. De acordo com Neves (1996), a pesquisa qualitativa visa "obter dados descritivos mediante contato direto e interativo do pesquisador com a situação objeto do estudo". Richardson (1999) ainda considera que o pesquisador pode utilizar "como material de estudo qualquer forma de comunicação, usualmente documentos escritos, como livros, periódicos, jornais, mas também, pode recorrer a outras formas de comunicação".

Este trabalho ainda assume a característica de um estudo de caso. De acordo com Yin (2001) o estudo de caso é escolhido "ao se examinarem acontecimentos contemporâneos, mas quando não se podem manipular comportamentos relevantes". Segundo Gil (2002) o estudo de caso consiste no "estudo profundo e exaustivo de um ou de poucos objetos, de maneira a permitir o seu conhecimento amplo e detalhado".

Os dados obtidos foram analisados sob a técnica de análise de conteúdo nos termos de Bardin (1997). A análise de conteúdo, de acordo com Bardin (1997) "é um conjunto de técnicas de análise das comunicações". O autor ainda completa: "não se trata de um instrumento, mas de um leque de apetrechos 
marcado por uma grande disparidade de formas e adaptável a um campo de aplicação muito vasto".

As categorias analíticas utilizadas advêm do trabalho de Mintzberg et al. (1976), os quais identificam doze elementos: três fases, três rotinas de suporte e seis fatores dinâmicos, que serão utilizados para sistematizar os resultados da pesquisa de campo, conforme destacados na Tabela 1.

Tabela 1: Elementos do processo decisório propostos por Mintzberg, Raisinghani e Theoret.

\begin{tabular}{|l|l|l|l|}
\hline Fases & Rotinas de Suporte & Fatores Dinâmicos \\
\hline Identificação & Controle & Interrupção & Atraso de agena \\
\hline Desenvolvimento & Comunicação & Ciclos de compreensão & Feedbacks \\
\hline Seleção & Políticas & Timming & Reciclagem de falhas \\
\hline
\end{tabular}

\section{RESULTADOS E DISCUSSÃO}

A pesquisa pretende identificar os elementos presentes no processo decisório acerca de um projeto de dupla titulação para um curso de bacharelado em Administração. O processo decisório acerca do projeto de dupla titulação envolve dois agentes principais: a coordenação de curso, responsável pela elaboração e validação do projeto; e o departamento de Relações Internacionais, responsável pela intermediação e negociação da proposta.

A proposta surge em decorrência de parcerias estabelecidas entre as instituições de ensino brasileira e portuguesa para oferta de módulos internacionais em cursos de pós-graduação. A demanda criada pelo Departamento de Relações Internacionais é endereçada ao coordenador de curso, que decidirá juntamente com o Núcleo Docente Estruturante (NDE), colegiado de Curso e Conselho Universitário a viabilidade ou não da proposta.

De acordo com o parecer CNE/CES no 56/2015, o Ministério da Educação não interfere nestes acordos e não há exigências de um credenciamento no MEC por parte das instituições. As exigências do Ministério da Educação apontam mais para critérios formais que facilitem o desenvolvimento do processo de cooperação como: a) existência de um convênio formal entre as universidades, b) cumprimento de toda a carga horária do curso, bem como das atividades formativas do currículo brasileiro, c) equivalência dos estudos realizados fora do Brasil e d) obrigação das Universidades, no momento de registrar o diploma, de verificar a legitimidade do processo e dos convênios que garantam a dupla diplomação.

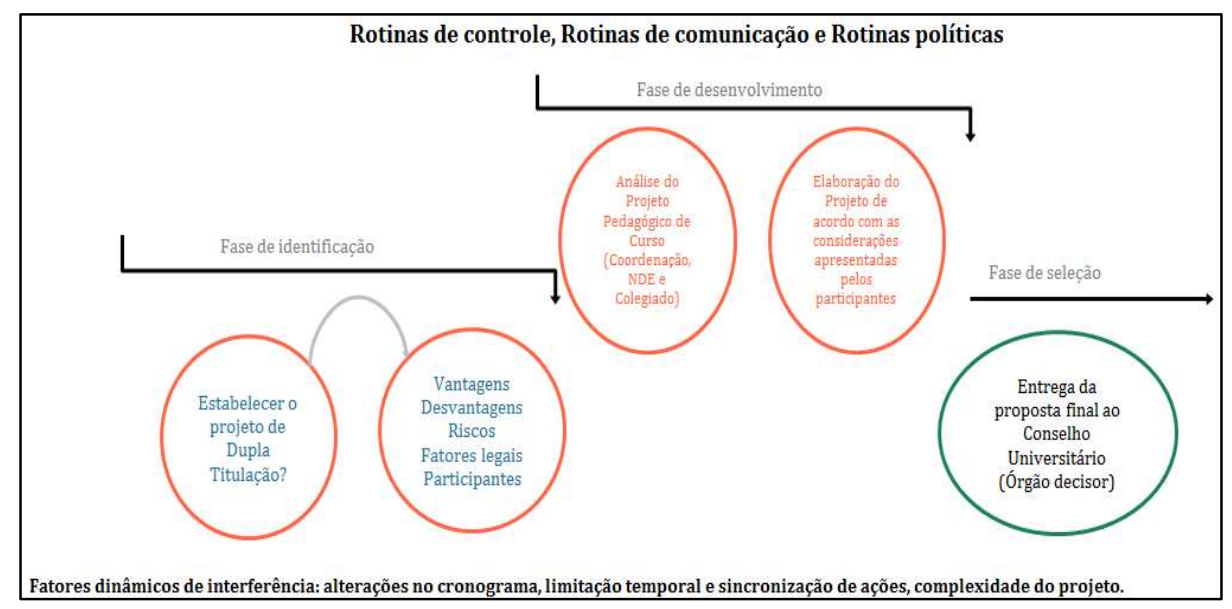

Figura 1: Elementos do processo decisório de dupla titulação. 
No primeiro momento, pode-se caracterizar como uma decisão por estímulo (MINTZBERG et al., 1996), tendo em vista que se trata de uma oportunidade advinda da parceria de longa data estabelecida entre as IES, que atenderá um público específico. A seguir, a figura 1 apresenta, de forma sintética, as fases, rotinas e fatores dinâmicos do processo decisório, que serão analisadas com maior detalhamento nas seções posteriores.

\section{Fases do processo decisório}

Mintzberg et al. (1976) ressaltam que a decisão é conceituada como o "compromisso com a ação" e o processo decisório como um conjunto de ações e de fatores dinâmicos, que começa com um estimulo para a ação e termina com um compromisso especifico em relação à ação. Os autores ainda consideram que as fases e rotinas do processo decisório ocorrem de forma não sequencial, podendo se repetir e se alterar. Para as fases do processo decisório foi utilizado o modelo trifásico: (a) identificação, (b) desenvolvimento e (c) seleção.

\section{Fase de identificação}

A fase de identificação inicia-se a partir do reconhecimento de que há uma decisão a ser tomada. Nesse sentido, o projeto de dupla titulação envolvendo o curso de bacharelado em Administração é viável?. A demanda endereçada pelo Departamento de Relações Internacionais é oportuna?. Permite-se adequar ao papel de formação profissional e social dos egressos do curso?. De acordo com Mintzberg et al. (1976), a fase de identificação compreende duas rotinas: o reconhecimento de decisões, no qual as oportunidades, problemas e crises são reconhecidos e sugerem a necessidade de decidir; e o diagnóstico, em que a gestão busca compreender os estímulos que determinam as relações causa-efeito para a situação de decisão.

Ao assumir a responsabilidade pelo projeto, a coordenação de curso compreende que o processo de formulação da proposta será longevo e necessitará de uma análise detalhada e compartilhada. Compartilhada no sentido de que a validação da proposta dar-se-á por outros agentes, com os quais terá que negociar: submeter a proposta ao Núcleo Docente Estruturante, que, se validada, segue para aprovação do Colegiado de Curso. No colegiado, deverá incorporar elementos que sustentem a viabilidade da proposta, negociar prazos, interesses e representantes que participarão da consecução do projeto. Terminado essa etapa, o coordenador leva a proposta ao Conselho Universitário, que validará ou não. Talvez haja influência por parte de outros interessados, como o Departamento de Relações Internacionais e a Reitoria.

\section{Fase de desenvolvimento}

A fase de desenvolvimento é, de acordo com Mintzberg et al. (1976), o coração do processo de tomada de decisão, compreendendo um conjunto de atividades que leva ao desenvolvimento de uma ou mais soluções para um problema ou uma crise ou para a elaboração de uma oportunidade. O coordenador analisará o projeto pedagógico de seu curso, bem como o projeto pedagógico do curso da IES estrangeira. Como o projeto é pioneiro na IESB, o coordenador terá que desenvolver sua própria solução. Ainda de acordo 
com a pesquisa realizada por Mintzberg et al. (1976), grande parte dos recursos de tomada de decisão são consumidos nessa etapa. O desenvolvimento pode ser descrito a partir de duas rotinas básicas: pesquisa, com vistas a encontrar soluções padronizadas; e de design, usadas para desenvolver soluções sob medida e/ou modificar soluções padronizadas anteriormente aplicadas.

A fase de desenvolvimento do projeto é longa. O coordenador inicia a pesquisa e tenta coletar o máximo de informações para iniciar o design do projeto. Sem um formato ideal, ou pronto, o coordenador inicia o projeto realizando uma análise superficial de equivalência de disciplinas, no tocante à carga horária. No segundo momento, convoca o Núcleo Docente Estruturante para realizar a equivalência do ementário e conteúdo programático. O segundo momento é prolongado, tendo em vista que os componentes do NDE (cinco professores) não conseguem entregar as tarefas no prazo, há conflitos internos e diferentes visões a despeito da equivalência das disciplinas e do rumo do projeto. $\mathrm{O}$ coordenador volta a assumir a maior parte do trabalho, preocupado com a possibilidade de o projeto voltar à 'estaca zero'. Assim, novos prazos são definidos, um novo acordo em relação ao prazo de entrega é negociado com o NDE e o Departamento de Relações Internacionais. As tarefas que não são entregues pelos representantes do NDE são realizadas pelo coordenador. Prevalece ainda uma longa fase de discussão interna: apresentar a proposta final ao NDE, validá-la no Colegiado de Curso e submetê-la à aprovação no Conselho Universitário. Enfim, a proposta é aprovada pelo Núcleo Docente Estruturante e segue para o Colegiado de Curso.

\section{Fase de seleção}

A fase de seleção é logicamente considerada como o último passo no processo de decisão. No entanto, Mintzberg et al. (1976) consideram que a fase de desenvolvimento envolve vários fatores acerca de uma decisão, por conseguinte, uma série de subdivisões que envolvem várias fases e processos. Essa fase acontece concomitantemente com o design do projeto. Na construção da proposta pela coordenação e NDE, várias alternativas vão sendo adotadas, construídas, descontruídas e validadas. No Colegiado de Curso, a proposta é novamente submetida à análise dos docentes. Surgem novas considerações, interrogações, propostas e outras decisões têm que ser tomadas. Essa análise e conclusão da proposta pelo Colegiado retarda a entrega final do Projeto ao Conselho Universitário e perde-se por dois dias o prazo para submissão. Depois de pouco mais de oito meses de discussão, a proposta seguirá para aprovação do Conselho Universitário, tendo em vista que suas deliberações ocorrem a cada dois meses.

\section{Rotinas de suporte do processo decisório}

Mintzberg et al. (1976) sugerem três conjuntos de rotinas de suporte das três fases centrais de um processo decisório: (a) rotinas de controle para orientar o próprio processo de decisão; (b) rotinas de comunicação, visando fornecer a informação de entrada e de saída necessárias para manter a tomada de decisões; e (c) rotinas políticas, permitindo que o tomador de decisão trabalhe uma solução em um ambiente influenciável. 


\section{Rotinas de decisão}

As rotinas de decisão envolvem a disponibilidade dos recursos para implementar sua decisão. Utiliza uma rotina de planejamento para avaliar o contingenciamento de recursos e estratégias para projetar um cenário ideal e uma rotina de mudanças para viabilizar a implementação dessa decisão. No primeiro momento, o coordenador do curso esboça um planejamento inicial dos recursos que necessitará para viabilizar a proposta, bem como as pessoas que estarão envolvidas no processo de negociação: colegiado, professores, gestores e outros departamentos.

\section{Rotinas de comunicação}

As rotinas de comunicação ocorrem durante todo o processo decisório, pois existe um fluxo ativo de comunicação, nos quais três rotinas são identificadas: (a) exploração, que sugere o reconhecimento do ambiente para estímulos, verificando a receptividade da proposta pelos professores, gestores e outros interessados; (b) investigação, que procura informações e diagnósticos sobre alternativas e suas consequências, que exige do coordenador o levantamento de um grande número de informações para legitimar a proposta e (c) disseminação, que propõe a transmissão da informação para facilitar e controlar o progresso do processo decisório e o envolvimento dos agente envolvidos. Nesse sentido, a coordenação informa aos envolvidos o a situação do processo, prazos, desafios e demais observações relevantes para consecução do projeto.

\section{Rotinas políticas}

As rotinas políticas refletem a influência exercida por indivíduos que procuram satisfazer suas necessidades pessoais ou de seu grupo em detrimento dos resultados que a decisão poderá causar. A rotina política se apresenta como imprescindível para o encaminhamento da proposta. Em busca do consenso, várias intervenções informais são realizadas: conversas individuais com os agentes envolvidos para buscar aliados e minimizar conflitos existentes (esse momento ocorre antes, durante e depois da formalização da proposta), reuniões fechadas com grupos contrários, iniciativas de intervenção com membros do Conselho Universitário, alianças internas com representantes da IESB. De acordo com Mintzberg et al. (1976), ficam evidentes as relações de poder em torno dos elementos presentes nas rotinas e fases do processo decisório. Cabe ressaltar que essas relações não se extinguem após a tomada de decisão.

\section{Fatores dinâmicos do processo decisório}

A delimitação de etapas em quase todo o processo de decisório mostra que não há uma constante progressão, sem perturbações, a partir de uma rotina para outra. Isso evidencia a dinamicidade do processo decisório operando em um sistema aberto, submetido a vários tipos de interferências de naturezas diversas. No processo decisório destacado, identificamos os aspectos propostos por Mintzberg et al. (1976), que serão destacados a seguir. 


\section{Interrupção}

A interrupção, caracterizada por eventos repentinos temporários ou definitivos. O cronograma foi alterado por duas vezes em virtude de eventos não presentes no calendário acadêmico: Congresso Internacional (em substituição à Semana Acadêmica) e defesa de tese de doutoramento por um dos representantes do NDE.

\section{Atraso de agenda}

O atraso de agenda, decorrentes da limitação temporal dos gerentes. Para atender a multiplicidade de tarefas que aguardam sua atenção, o processo de tomada de decisão é relegado a segundo plano em detrimento de outras atividades. O coordenador precisa se ocupar com o cumprimento do projeto do curso, com o atendimento a docentes e discentes, cumprimento dos prazos acadêmicos, participação em tomadas de decisão de outras frentes. Considera-se também o fato de que a proposta foi estabelecida no último dia de expediente da coordenação, impossibilitando a ação do coordenador durante o período de férias (trinta dias). O cronograma foi alterado por sete vezes, sendo três apenas no segundo mês.

\section{Ciclos de compreensão}

Os ciclos de compreensão, tendo em vista que o processo decisório não é considerado como um processo linear, mas circular, no qual fatores que interferem o processo de decisão trazem o ciclo de volta para fases anteriores. De acordo com os autores, diante da complexidade do processo decisório, a estruturação do processo pode alternar entre a seleção e desenvolvimento de conciliar objetivos com alternativas e meios e fins. Diante da falta de um modelo ou padrão de como fazer, a fase de compreensão do processo gerou retrabalho, conflitos e, por alguns momentos, a possibilidade de extinção do projeto. Tendo em vista que o projeto de dupla titulação é piloto na instituição, muitas dúvidas surgiram na face de design.

\section{Feedbacks}

Os feedbacks dos resultados de uma ação anterior de um processo decisório precisam ser analisados por outros decisores. Cada passo no processo decisório envolve atividades demoradas e reavaliação de alguns passos. Mesmo dispondo de formas de comunicação eletrônicas e ágeis, a maioria dos feedbacks eram discutidos somente nas reuniões agendadas.

\section{Timming}

O timming é aparentemente um grande fator na tomada de decisões estratégicas. Os decisores podem propositadamente acelerar ou atrasar um processo de decisão para tirar proveito de circunstâncias especiais com o objetivo de amadurecer a decisão. Quando da comunicação de realização do Congresso Internacional por parte da Gestão, o coordenador solicitou duas reuniões extraordinárias na semana anterior 
à realização do evento. Essa ação conferiu celeridade ao processo, fazendo com que o mesmo fosse aprovado pelo NDE no final da segunda reunião. De acordo com Mintzberg et al. (1976), os decisores fazem isso para aguardar suporte ou melhores condições, para sincronizar a ação com outra atividade, para efeito de surpresa, ou para ganhar tempo. Em geral, controlam o tempo de maturidade do processo, visando adiantar ou atrasar determinados eventos. Após aprovação, o projeto foi encaminhado para o Colegiado de Curso na semana de realização do Congresso Internacional, o que proporcional aumentar o prazo de análise desse órgão em uma semana a mais.

\section{Reciclagem de falhas}

A reciclagem de falhas, considerando que os processos de decisão são, por vezes, bloqueados por falta de uma solução aceitável. As soluções podem ser rejeitadas na avaliação da escolha como tendo uma baixa recompensa, restrições que não podem satisfazer. Na falta de uma solução aceitável, o decisor pode simplesmente extinguir o processo ou, ainda, alterá-lo para viabilizar sua aceitação. O projeto apresentou falhas relativas à algumas equivalências: duas disciplinas do núcleo comum tinham ementário com similaridade de apenas $40 \%$ em relação ao equivalente na IESE. Esse fator quase extinguiu o projeto, sendo reavaliado pela coordenação e NDE para alteração da proposta e validação.

\section{CONCLUSÕES}

O presente artigo objetivou identificar elementos presentes no processo decisório para estabelecimento de um curso bacharelado com dupla titulação envolvendo duas instituições de ensino, utilizando-se os doze elementos básicos propostos por Mintzberg et al. (1976) para uma análise empírica. Com relação ao processo decisório, a pesquisa confirma a complexidade envolvida na busca de solução e decisão para determinado problema/situação. Com referência ao estudo de caso, destaca-se o ambiente em que a situação é investigada. As Universidades são marcada por atores que possuem perfis, comportamentos e interesses distintos, agrupados em vários sistemas não articulados, indo ao encontro dos estudos propostos por Weick (1976), Orton et al. (1990), Hatch (1997), Eisenhardt et al. (1992).

Em relação às fases do processo decisório, a fase de desenvolvimento é a mais longeva, corroborando os achados de Mintzberg et al. (1976), exigindo muito trabalho do coordenador do projeto em virtude do retrabalho proporcionado pelos ciclos de compreensão do projeto. Considerando a fase de seleção, merece destaque a rotina de autorização, na qual as decisões são autorizadas por um indivíduo que não possui autoridade para implantá-la, devendo esta recorrer a estâncias superiores na organização. Esse ponto é fundamental para o cumprimento do cronograma de consecução do projeto e, por vários momentos, independe da vontade ou atuação do coordenador.

A despeito das rotinas de suporte do processo decisório, o planejamento dos recursos e pessoas envolvidas, a acessibilidade às informações do processo e a disseminação da comunicação conferiram celeridade para o andamento do projeto. Cabe destaque para as atividades políticas, imprescindíveis para o encaminhamento da proposta. Por ser uma proposta inovadora, ambígua e complexa, as intervenções 
informais conseguiram fazer com que houvesse consenso em relação a busca por soluções e decisão quanto a viabilidade do projeto. Outro ponto que merece realce é a quantidade de informações, pareceres e percepções advindas dessas ações informais. Alguns participantes do processo se sentiam mais à vontade para expor suas ideias individualmente, sem a presença do grupo de estudos da proposta.

Pode-se identificar a interferência de todos os fatores dinâmicos propostos por Mintzberg et al. (1976), com maior realce para os atrasos, tendo em vista a multiplicidade de interesses e afazeres dos envolvidos e com menor destaque para as interrupções. Os eventos não presentes no calendário acadêmico não agravaram o cumprimento do cronograma, considerando que o evento relativo ao Congresso Internacional proporcionou maior tempo de análise da proposta pelo Colegiado de Curso. Em relação ao cronograma, cabe informar que ele foi alterado por sete vezes e, para fins de compreensão do caso em estudo, considerar-se-á a última versão.

Constata-se que o projeto de dupla titulação envolvendo as duas instituições de ensino apresentam diversos atores, diferentes estratégias e interesses. Nesse sentido ficam evidentes as relações de poder em torno dos elementos presentes nas rotinas e fases do processo decisório. Cabe ressaltar que essas relações não se extinguem após a tomada de decisão e validação da proposta. A investigação identifica que o processo decisório possui um alto nível de complexidade, principalmente ao considerar os fatores dinâmicos que o influenciam e os agentes envolvidos na tomada de decisão.

Como limitações do estudo, considera-se o fato de que a pesquisa é um estudo de caso, e, conforme Yin (2001), os resultados encontrados não podem ser generalizados, pois levam em consideração a população pesquisada, as condições iniciais de trabalho e o meio de observação utilizados. Ressalta-se também o fato de que o pesquisador é um dos agentes do processo em estudo. Mesmo com todo o cuidado e rigor acadêmico, a presença do pesquisador pode inibir os demais participantes do processo e levar a uma representação parcial da realidade.

Como sugestões para futuras pesquisas, considera-se relevante discutir outras variáveis que afetam o processo decisório que não foram objeto desse estudo, conforme exposto por Pettigrew (1977), que consiste na análise de um processo cujas mudanças se dão em nível horizontal e vertical de análise e por meio de interconexões entre os níveis, durante todo o tempo. Torna-se interessante visualizar o caso em estudo a partir de outras teorias, como garbage can (COHEN et al., 1972) ou pela ótica dos loosely coupled systems (ORTON et al., 1990). Diante dos vários achados na seção de rotinas políticas, a dimensão política torna-se um grande universo de análise para a busca de elementos presentes em um processo decisório, aplicável nas mais variadas situações.

\section{REFERÊNCIAS}

BARDIN, L.. Análise de conteúdo. Lisboa: 70, 1997.

COHEN, M. D.; MARCH, J. G.; OLSEN, J. P.. A garbage can model of organizational choice. Administrative science quarterly, v.17, n.1, p.1-25, 1972.

EISENHARDT, K. M.; ZBARACKI, M. J.. Strategic decision making. Strategic management journal, v.13, n.S2, p.17-37, 1992.

GIL, A. C.. Como elaborar projetos de pesquisa. 4 ed. São Paulo: Atlas, 2002.

HATCH, M. J.. Organization theory: modern, symbolic and 
postmodern perspectives. Oxônia: Oxford university press, 1997.

MARCH, J. G.. The business firm as a political coalition. The Journal of Politics, v.24, n.4, p.662-678, 1962.

MINTZBERG, H.; RAISINGHANI, D.; THEORET, A.. The structure of "unstructured" decision processes.

Administrative Science Quarterly, v.21, n.2, p.246-275, 1976.

MORGAN, G.. Imagens da Organização. São Paulo: Atlas, 1996.

NEVES, J. L.. Pesquisa qualitativa: características, usos e possibilidades. Caderno de pesquisas em administração, São Paulo, v.1, n.3, p.2, 1996.

ORTON, J. D.; WEICK, K. E.. Loosely coupled systems: A reconceptualization. Academy of management review, v.15, n.2, p.203-223, 1990.

PETTIGREW, A. M.. Strategy formulation as a political process. International Studies of Management \& Organization, v.7, n.2, p.78-87, 1977.
PFEFFER, J.; SALANCIK, G. R.. The external control of organizations: A resource dependence perspective. Redwood City: Stanford University Press, 2003.

RAUPP, F. M.; BEUREN, I. M.. Metodologia da pesquisa aplicável às ciências sociais. São Paulo: Atlas, 2003.

RICHARDSON, R. J.. Pesquisa social: métodos e técnicas. 3 ed. São Paulo: Atlas, 1999.

SIMON, H. A.. Comportamento Administrativo. Rio de Janeiro: FGV, 1965.

SPELLER, P.; TRUJILLO, A. M.. O Brasil e as modalidades de Cooperação Acadêmica. In: Novas Formas de Cooperação: Espaços de Convergência nos Países Lusófonos. Bragança: AULP, 2011.

YIN, R. K.. Estudo de caso: planejamento e métodos. São Paulo: Bookman, 2001.

WEICK, K. E.. Educational organizations as loosely coupled systems. Administrative Science Quarterly, v.21, n.1, p.1-19, 1976.

A CBPC - Companhia Brasileira de Produção Científica (CNPJ: 11.221.422/0001-03) detém os direitos materiais desta publicação. Os direitos referem-se à publicação do trabalho em qualquer parte do mundo, incluindo os direitos às renovaç̃̃es, expansões e disseminações da contribuição, bem como outros direitos subsidiários. Todos os trabalhos publicados eletronicamente poderão posteriormente ser publicados em coletâneas impressas sob coordenação da Sustenere Publishing, da Companhia Brasileira de Produção Científica e seus parceiros autorizados. Os (as) autores (as) preservam os direitos autorais, mas não têm permissão para a publicação da contribuição em outro meio, impresso ou digital, em português ou em tradução. 